\title{
Relações entre atividades sensoriais e artefatos culturais na apropriação de práticas matemáticas de um aprendiz cego
}

\section{Relations between sensory activities and cultural artefacts in the appropriation of mathematical practices of a blind learner}

\author{
Lulu Healy ${ }^{1}$ \\ Solange Hassan Ahmad Ali Fernandes ${ }^{2}$
}

\begin{abstract}
RESUMO
Neste artigo, exploramos a natureza social e corporificada da cognição matemática, argumentando que a apropriação de práticas matemáticas envolve a coordenação de fala, gestos, objetos materiais e atividades sensoriais. Utilizando um quadro teórico em desenvolvimento, no qual tentamos combinar aspectos das perspectivas socioculturais de Vygotsky e Leontiev, com abordagens mais recentes da neurociência da cognição humana, investigamos como um estudante cego, interagindo com uma professora (pesquisadora), chegou a conhecer aspectos da matemática em questão (simetria e reflexão), por um processo que envolve a simulação mental de experiências passadas. Exploramos também o papel da pesquisadora no sentido de facilitar um tipo de entrelaçamento entre cultura e cognição, convidando o aluno a fazer conexões entre as experiências sensoriais (passado e presente), artefatos de representação e significados matemáticos culturalmente aceitos.

Palavras-chave: cognição corporificada e gestos; mediação; aprendizes de matemática cegos; simulação; simetria.
\end{abstract}

ABSTRACT

1 Universidade Bandeirante de São Paulo - UNIBAN. Av. Braz Leme, 3029, São Paulo, SP, Brasil, CEP 02022-011. E-mail: lulu@pq.cnpq.br

2 Universidade Bandeirante de São Paulo - UNIBAN. Av. Braz Leme, 3029, São Paulo, SP, Brasil, CEP 02022-011. E-mail: solangehf@gmail.com 
In this paper, we examine the claim that mathematical cognition is both an embodied and social endeavour by exploring the co-ordinations of speech, gestures, material objects and sensory activities in a dialogue between a mathematics teacher (researcher) and a blind student. Using a developing theoretical framework in which we attempt to combine aspects of the socio-cultural perspectives of Vygotsky and Leontiev with more recent neuroscientific approaches to human cognition, we argue that the student came to know aspects of the mathematics in question (symmetry and reflection), in a process involving the mental simulation of past experiences in ways which enabled associations between physical and mathematical activities. We also explore the role of the researcher in facilitating a kind of entanglement between culture and cognition by inviting the learner to make connections between sensory experiences (past and present), representational artefacts and culturally accepted mathematical meanings.

Keywords: embodied cognition and gestures; mediation; blind mathematics learners; simulation; symmetry.

\section{Introdução}

Nossos estudos com aprendizes com necessidades educacionais especiais têm nos conduzido à busca de compreender como o corpo influencia os processos desencadeados no cérebro, e vice-versa ${ }^{3}$. Para nós, a importância e o papel do corpo para a cognição são inquestionáveis, mas ainda pouco sabemos sobre como explorar o potencial do corpo para favorecer os processos cognitivos daqueles que não dispõem de todos os canais perceptivos. As perspectivas dos pesquisadores que discutem a natureza "corporificada" de cognição (BARSALOU, 2008; GALLESE; LAKOFF, 2005; OAKLEY, 2007; DAMÁSIO, 2005 , e.g.) começam a permear o campo de Educação Matemática, oferecendo novas maneiras de interpretar os processos associados à apropriação de práticas matemáticas. Um ponto de partida é assumir uma postura interacionista, como a proposta por Gallese e Lakoff (2005), na qual o que sabemos é resultado do nosso constante encontro e interação com o mundo via nosso corpo e cérebro.

Nessa mesma linha, de acordo com Barsalou (2008), são nossas experiências perceptivas que nos permitem formular representações multimodais, as

3 Estas pesquisas contam com o apoio da Fundação de Amparo à Pesquisa do Estado de São Paulo (FAPESP), Processo N.o 2004/15109-9 e da Coordenação de Aperfeiçoamento de Pessoal de Nível Superior (CAPES), Processo N.o 23038.019444/2009-33. 
quais são armazenadas em nossa memória e reativadas para simular estados de percepção, ação e introspecção quando uma categoria não está presente fisicamente, ou seja, desencadeiam estados perceptivos associados a ela no passado. Oakley (2007) e Damásio (2005) denominam essas representações multimodais de imagens que condensam modalidades sensoriais resultantes de experiências perceptivas da visão, da audição, do sistema háptico, motor, olfativo e gustativo. Independentemente do termo - representações multimodais ou imagens - são esses os recursos que nos permitem simular.

No contexto de situações instrucionais, consideramos que o processo de simulação pode ter um papel didático; ou seja, um processo a ser explorado pelo professor de forma a fazer emergir o que Vygtosky (1998b) denota como zona de desenvolvimento proximal. De fato, o trabalho do Vygotsky é de suma importância em nossa busca por uma compreensão mais profunda da aprendizagem matemática de alunos com necessidades educacionais especiais. Neste artigo apresentamos um ensaio para relacionar a perspectiva de Vygotsky (1987, 1998a, 1998b) às contemporâneas que reconhecem a reciprocidade entre corpo, cognição e os recursos através dos quais atividades matemáticas são realizadas.

\section{Defectologia $^{4}$ e mediação}

Os primeiros trabalhos de Vygotsky na área de educandos com necessidades especiais, ou Defectologia como foi denominado na época, foram publicados em 1924, período em que trabalhou no Instituto de Psicologia Experimental de Moscou ocupando-se da educação social de crianças surdas e cegas (van der VEER; VALSINER, 1996). Uma característica desses trabalhos é o destaque dado à importância da educação social de crianças deficientes e ao potencial dessas crianças para um desenvolvimento normal. Em seus estudos, propõe que a criança com necessidades especiais seja estudada sob uma perspectiva qualitativa e não como uma variação quantitativa da criança "normal". Nesse período, seus escritos eram carregados de otimismo, destacando que a cegueira e a surdez nada mais eram do que a falta de uma das possíveis vias de acesso ao ambiente, e que a solução consistia em substituir uma via tradicional por outra. Entre 1924 a 1926, várias ideias que posteriormente teriam importância primária nos trabalhos de Vygotsky foram apresentadas e defendidas, entre

4 Termo usado por Vygotsky (1997) para denominar a ciência que estuda os processos de desenvolvimento de crianças que apresentam deficiências físicas, mentais ou múltiplas. 
elas a distinção que implicitamente ele faz entre signo e significado e a ideia do olho e da fala serem "instrumentos" para ler e pensar respectivamente. O que, segundo van der Veer e Valsiner (1996), indica a primeira formulação do conceito de mediação.

Vygotsky atribuía papel central aos instrumentos de natureza semiótica. Dentre estes, ocupou-se centralmente da fala como via principal para a análise das raízes genéticas do pensamento e da consciência.

[...] a criança, com auxílio da fala, cria um campo temporal que lhe é tão perceptivo e real quanto o visual. A criança que fala tem, dessa forma, a capacidade de dirigir sua atenção de uma maneira dinâmica. Ela pode perceber mudanças na sua situação imediata do ponto de vista de suas atividades passadas, e pode agir no presente com a perspectiva do futuro (VYGOTSKY, 1998a, p. 47).

É essa interação entre os participantes de uma atividade instrucional que pode fazer emergir uma zona de desenvolvimento proximal (ZDP) que, segundo o mesmo autor, é um espaço no qual a criança pode trabalhar (no presente) além do seu nível de desenvolvimento real, característico das habilidades que ela já havia dominado (no passado), atingindo seu nível de desenvolvimento potencial; ou seja, o que a criança pode realizar com a cooperação de indivíduos mais capazes e que caracteriza um desempenho futuro (VYGOTSKY, 1998). Para ele, a fala permite à criança o controle verbal de sua atenção, o que lhe possibilita reorganizar seu campo perceptivo. "O campo de atenção da criança engloba não uma, mas a totalidade das séries de campos perceptivos potenciais que formam estruturas dinâmicas e sucessivas ao longo do tempo." (VYGOTSKY, 1998a, p. 47). O que corrobora a tese de Gallese e Lakoff (2005), para os quais a linguagem é inerentemente multimodal por integrar várias modalidades como ver, ouvir, tocar, ações motoras e outras.

A ideia de mediação semiótica, central em Vygotsky, funda-se não só na fala oral, mas em situações interativas, nas quais instrumentos, gestos, signos e outros elementos que fazem parte do meio transformam processos interpessoais em intrapessoais. A centralidade da semiose nas relações entre o individual e o mundo vem sendo discutida há séculos nas mais diversas áreas de conhecimento. A título de exemplo, Condillac (1715-1780) declarou que um conhecimento só poderia ser alcançado se determinada sensação relacionava-se a outras através dos signos. Ele caracterizou a linguagem oral como um conjunto sistematizado de signos que torna possível a formação de conceitos. Joseph-Marie Degérando 
(1772-1842) considerava que são três os meios naturais que o homem dispõe para traduzir o pensamento,

[...] o primeiro esta nos movimentos de seu corpo; o segundo nos órgãos da voz; o terceiro nos objetos exteriores [...]. Daí resultaram [...] os três sistemas de linguagem que chamamos a linguagem da ação, a fala e a escritura (CONDILLAC; DEGÉRANDO, 1989, p. 217).

A citação acima, datada do século XVIII, mostra indícios do destaque dado aos gestos, à linguagem oral e aos registros (semióticos ou não) para a cognição humana. Nela, pode-se perceber a importância dada aos produtos oferecidos pelo corpo - sensações e percepções - para o desenvolvimento cognitivo.

Contemporâneo de Vygotsky, Leontiev (1978) discute a percepção com base na teoria da cognição de Marx, que defende a ideia de que a atividade é a base para a cognição humana. Segundo Leontiev (1978), ao apropriar-se de um instrumento, o homem incorpora as necessidades e capacidades humanas que ali foram objetivadas de geração em geração, ou seja, se apropria das riquezas acumuladas nos instrumentos. Ele denomina esse processo de apropriação, o que de forma simplista indica a ação de fazer seu o que já é dos outros. Todo processo de apropriação, no caso, o processo cognitivo, é mediado por signos iniciando-se por estimulações externas que solicitam o concurso de um ou de vários de nossos órgãos sensoriais, na forma de signos. Em seguida, o processo continua pela interpretação e transformação dos signos em outros e assim sucessivamente até a formulação do pensamento conceitual.

Falando sobre a psicologia dos processos cognitivos, possivelmente influenciado por seus trabalhos na área da Defectologia e ainda sob o aporte marxista, Leontiev postula que o potencial da percepção depende da estrutura dos órgãos dos sentidos. Entretanto para que uma imagem sensível - visual ou tátil - possa ser concebida é necessário um relacionamento ativo entre o homem e o objeto.

O ser humano vive como se fosse num círculo cada vez mais amplo de atividade para si. No começo, é um pequeno círculo de pessoas e objetos que diretamente o circundam: ele desenvolve interação com eles, uma percepção sensorial deles, uma aprendizagem do que pode ser conhecido sobre eles, um aprendizado de seu significado. Porém, mais para frente, diante de si começa a se abrir uma atividade que se encontra muito além 
dos limites de sua atividade prática e de seu contato direto: os limites ampliados daquilo que ele pode conhecer e que é apresentado para ele pelo mundo. O "campo" real que agora determina suas ações não é aquele que está simplesmente presente, mas aquele que existe para ele, existe objetivamente ou, às vezes, apenas como uma ilusão (LEONTIEV, 1978, Formação da personalidade, tradução nossa).

Podemos identificar certa convergência entre a citação de Leontiev e a posição mais recente de Gallese e Lakoff (2005): para ambos, as ações sobre objetos não presentes trazem, para o presente, sensações e percepções. Para Gallese e Lakoff, essas percepções são modalidades sensoriais que se integram umas com as outras e com o controle motor e planejamento. Tanto para Gallese e Lakoff como para Vygotsky e Leontiev, atividades perceptivas também estão intimamente ligadas às experiências com o meio sócio-histórico e cultural vividas por cada um.

Isso sugere que podemos esperar que as ações de uma pessoa que não enxerga com seus olhos diferem daquelas de uma pessoa com acesso ao campo visual. Entretanto, uma questão interessante a considerar, no caso de cegueira adquirida, seria a seguinte: qual o papel das modalidades sensoriais associadas ao seu passado como vidente nas suas atividades atuais?

\section{O estudo}

O sujeito de pesquisa das atividades experimentais discutidas neste artigo é portador de cegueira adquirida. Edson, nome fictício que lhe demos, perdeu totalmente a visão do olho esquerdo com quatro anos de idade. Mesmo depois de treze cirurgias para salvar o olho direito, aos quinze anos, após um descolamento da retina ficou com dois por cento de visão no olho direito, o que o possibilita ter percepção e projeção luminosas ${ }^{5}$. No período do desenvolvimento desta pesquisa, cursava a terceira série do Ensino Médio em uma escola estadual no período noturno, inserido em classe comum, e trabalhava como recepcionista. Suas imagens são aqui reproduzidas com concordância dele, já que é maior de idade.

A fim de estabelecer uma variedade de entendimentos a respeito da capa-

5 No primeiro caso (percepção), há apenas a distinção entre claro e escuro: no segundo (projeção) o indivíduo é capaz de identificar também a direção de onde provém a luz (CONDE, 2004). 
cidade cognitiva e dos processos cognitivos do sujeito envolvido nesta pesquisa, optamos pelo método da dupla estimulação de Vygotsky (1998), onde o sujeito é colocado "frente a uma tarefa que excede em muito os seus conhecimentos e capacidades" (COLE; SCRIBNER, 1998, p. 18). Essa tarefa é proposta dentro de uma situação estruturada e o sujeito recebe uma orientação ativa, por parte do pesquisador, no sentido da construção de uma estratégia (que ainda não existia para o sujeito) para a realização da tarefa (van der VEER; VALSINER, 1996).

No estudo aqui apresentado, o primeiro estímulo foi dado pelas ferramentas materiais e o segundo estímulo foi oferecido pela pesquisadora através de intervenções. Realizamos uma série de entrevistas baseadas em tarefas, considerando pesquisas anteriores, sobre as noções de reflexão por sujeitos com acuidade visual dentro dos padrões normais (HEALY, 2002; GRENIER, 1988; KÜCHEMANN, 1981). Tais entrevistas foram realizadas em três sessões de aproximadamente uma hora e trinta minutos que foram videogravadas e transcritas em sua totalidade para facilitar as análises.

Na primeira entrevista, ao ser questionado sobre memória visual, afirmou tê-la e não apresentar dificuldades para reconhecer formas que conheceu quando ainda podia ver, mesmo que as tenha conhecido no período de baixa visão. Deste modo, possuía memória visual - elementos do passado - que poderia ser suscitada nos diálogos quando necessário. Em relação à Geometria mostrou conhecer ao menos nominalmente alguns elementos que foram fundamentais para o desenvolvimento dos diálogos, como: ponto médio, bissetriz e perpendicular.

O objeto matemático em estudo nas atividades descritas neste artigo foram figuras geométricas simétricas e reflexão por um eixo. Para ambos os estudos um conceito fundamental é o eixo de simetria. Assim, para que o sujeito pudesse realizar sequência de tarefas que seriam desenvolvidas durante as sessões, centramos, inicialmente, nossa atenção no estudo de figuras simétricas com o objetivo de levar o sujeito a apropriar-se do conceito de eixo de simetria e suas propriedades.

\section{Atividades experimentais e análises}

As tarefas iniciais envolviam a determinação do eixo de simetria de figuras feitas em papel canson (Figura 1), e a estratégia utilizada pelo sujeito foi a comparação das formas determinadas por dobraduras. Ao final da atividade, o vinco determinado na figura foi denominado eixo de simetria. 


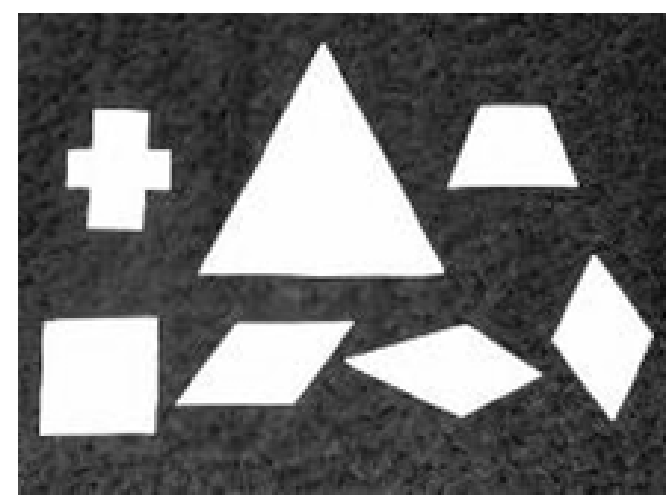

FIGURA 1 - POLÍGONOS EM PAPEL CANSON

As tarefas seguintes consistiam em determinar o eixo de simetria de figuras construídas numa prancha de desenho, e foi durante a realização dessas atividades que emergiu, pela primeira vez, o imaginar e o simular. A tarefa descrita abaixo consistia em representar os eixos de simetria de um hexágono na prancha de desenho, o que impedia o uso da estratégia de dobrar para determinar o eixo de simetria.

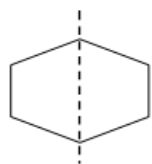

Figura $2 \mathrm{a}$

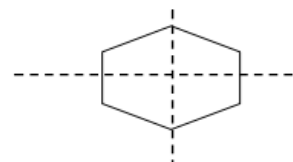

Figura $2 b$

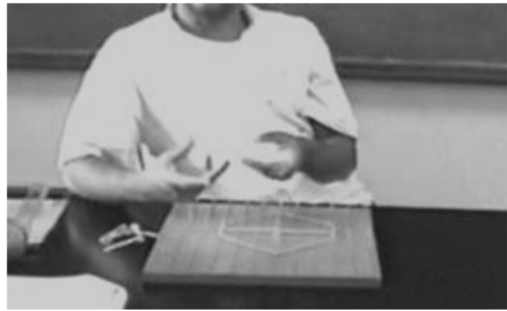

Figura 2c

FIGURA 2 - POLÍGONOS EM PAPEL CANSON

Edson ${ }^{6}$ : Aqui tá um eixo de simetria. Certo? (Figura 2a).

Edson: Aqui tem mais. Dois, certo? Tem dois eixos de simetria (Figura 2b).

Pesquisadora: Dois eixos de simetria. Não tem mais nenhum? Edson: Eu estou fazendo na cabeça. Não dá para fazer mais nenhum. Pesquisadora: Não dá por quê?

Edson: Primeiro eu usei o tato para ter noção do desenho. Agora eu estou usando a cabeça, como se eu estivesse dobrando com a mão.

6 Edson é denominação fictícia do participante. 
Pesquisadora: Você está imaginando a figura?

Edson: Isso, visualmente. Para cá um e para cá dois. (Simula a dobradura da figura) Tem só dois mesmo (Figura 2c).

O procedimento declarado por Edson denota que através do tato ele formulou uma imagem visual como ele a denominou - a figura representada na prancha foi imaginada em papel, e a partir dessa imagem fez simulações imaginativas $^{7}$ (dobraduras), na concepção de Gallese e Lakoff (2005), ou simples simulações de acordo com Barsalou (2008). Essas realizações permitiram a ativação de recursos multimodais formulados no passado próximo, enquanto ele trabalhava com as figuras em papel. Isso fica evidente na terceira fala de Edson, apresentada nesse trecho, onde ele fala sobre $a$ imagem mental formulada a partir da exploração tátil, que o permitiu manipular mentalmente a forma geométrica. Imaginando as dobras que poderiam ser feitas nessa figura, de tal forma que houvesse congruência entre as duas partes, Edson realiza a tarefa com êxito na primeira tentativa.

As tarefas seguintes tinham o objetivo de estudar o conceito de reflexão como uma transformação geométrica, e foram estruturadas para o estudo de reflexão de figuras segundo um eixo. Edson recebe a proposta de determinar a imagem do triângulo (Figura 3). A tarefa é realizada com sucesso numa segunda tentativa e, para fazer a verificação da sua construção, em sua ação percebe-se que ele conta o número de pinos que ficaram no interior dos dois triângulos para certificar-se de que é mesmo o que caracterizaria para ele a congruência entre a forma dada e sua imagem.

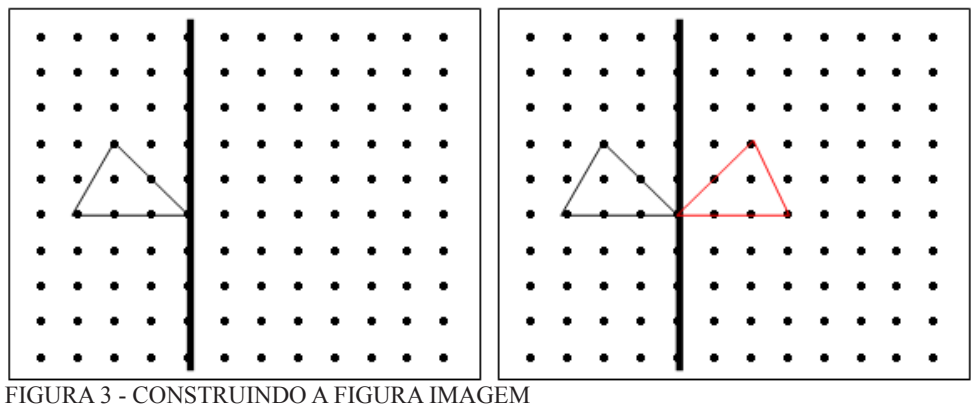

A pesquisadora pede que Edson justifique a posição dos vértices simétricos que não pertencem ao eixo de simetria. Ao perceber a dificuldade do sujeito em estabelecer relações, a pesquisadora decide provocar uma situação de simula-

7 São aquelas que podem realizar raciocínios conceituais, bem como ações e percepções. 
ção recorrendo à memória visual de Edson, numa tentativa de conectar pontos simétricos a imagens no espelho - conceitos do passado não mais acessíveis fisicamente no caso do aprendiz.

Pesquisadora: Na sua memória visual você tem a sua imagem no espelho? Edson: Sim.

Pesquisadora: Como é que você via a sua imagem no espelho?

Edson: Como assim?

Pesquisadora: Por exemplo: se você está na frente do espelho e levanta sua mão direita a sua imagem levanta que mão?

Edson: Se eu levantar a esquerda levanta a esquerda. Se eu levantar a direita levanta a direita.

Pesquisadora: Sim é claro. Mas a sua imagem fica de frente para você. Faz de conta que eu sou sua imagem no espelho. Estou de frente para você. Levanta sua mão esquerda. Para eu tocar a sua mão, eu tenho que levantar que mão?

Edson: A direita. É mesmo inverte.

Parece-nos que esta intervenção da pesquisadora, conectando a memória visual do passado do sujeito à situação presente, motivou uma re-concepção do termo eixo de simetria, e fez emergir um campo simbólico temporal (ZDP), onde o diálogo instrucional desenvolve-se com mais facilidade. Segundo Barsalou (2008), a simulação é a recriação dos estados perceptivos, sensório motor e introspectivo, adquiridos durante a experiência com o mundo, corpo e mente. A experiência de Edson com espelhos, quando ele ainda podia ver, permitiulhe formular uma representação multimodal, que favoreceu a representação imaginária, nesse caso, de uma categoria que não pode mais estar presente fisicamente para ele. A intervenção da pesquisadora o fez reativar essa representação multimodal estruturada durante a experiência para simular os estados de percepção, ação e introspecção associados a ela no passado - sua própria imagem no espelho. A discussão sobre a posição da imagem no espelho fez com que Edson se lembrasse que a imagem aparece invertida. Numa das sessões anteriores, ele já havia percebido a inversão de orientação quando o objeto de estudo eram figuras simétricas, mas não conseguia conectar essa propriedade às imagens obtidas por reflexão em torno de uma reta.

"O eixo de simetria faz a divisão em dois lados iguais. E a figura fica dividida em duas iguais". 
Na sequência, iniciamos o trabalho com reflexão de segmentos em torno de uma reta. De modo geral as tarefas foram realizadas com sucesso, mesmo precisando, algumas vezes, de mais de uma tentativa. O primeiro impasse aconteceu na determinação do segmento-imagem a partir do segmento-dado como representado na figura abaixo (Figura 4).

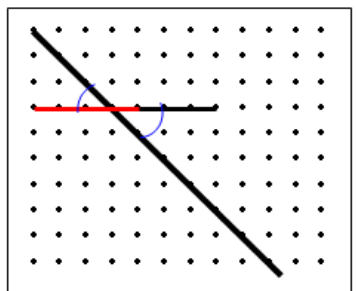

a

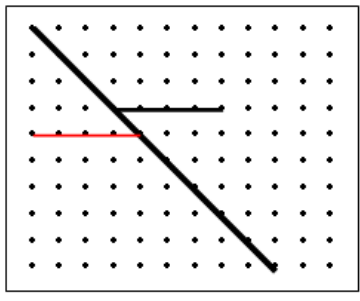

$\mathrm{b}$

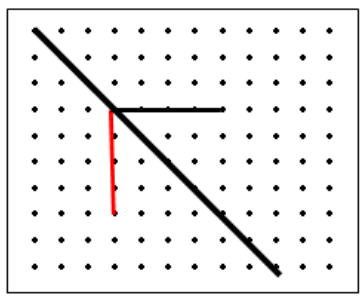

c

FIGURA 4 - CONSTRUINDO SEGMENTO-IMAGEM

Edson, ao justificar sua resposta (Figura 4a), considera ter mantido a congruência entre as medidas dos segmentos e entre os ângulos que esses formam com o eixo de simetria. Para ele, a congruência entre os ângulos opostos pelo vértice bastava para garantir a imagem. Depois de discutir as medidas dos ângulos, Edson representa sua imagem como mostramos na Figura 4b. O impasse só foi superado quando a pesquisadora provocou novamente uma situação de simulação.

Pesquisadora: Quando você tem a imagem no espelho, se você encosta o dedo no espelho a sua imagem encosta o dedo no espelho também, e você tem a impressão que sua imagem encosta o dedo no seu dedo.

Edson: Sim.

Pesquisadora: Aqui o eixo de simetria é como se fosse o espelho e esse ponto aqui (ponto sobre o eixo de simetria) é como se fosse o seu dedo. Edson: Tá errado. (Realiza a tarefa com êxito - Figura 4c)

Gallese e Lakoff (2005) destacam que as simulações imaginativas geradas por ações, percepções ou imaginação, são realizadas a partir da ativação temporal de processos cerebrais criados em situações do passado. As ações de Edson sobre a prancha de desenho sugerem que ações do passado foram recriadas. Ele passou a construir o segmento imagem determinando cada um dos pontos representados e sua respectiva imagem como se os pudesse ver através de um espelho. Isso nos motivou a propor figuras que pareciam ser mais ousadas (Figura 5), e a estratégia de construir a imagem ponto a ponto o levou a realizar as tarefas com precisão. 

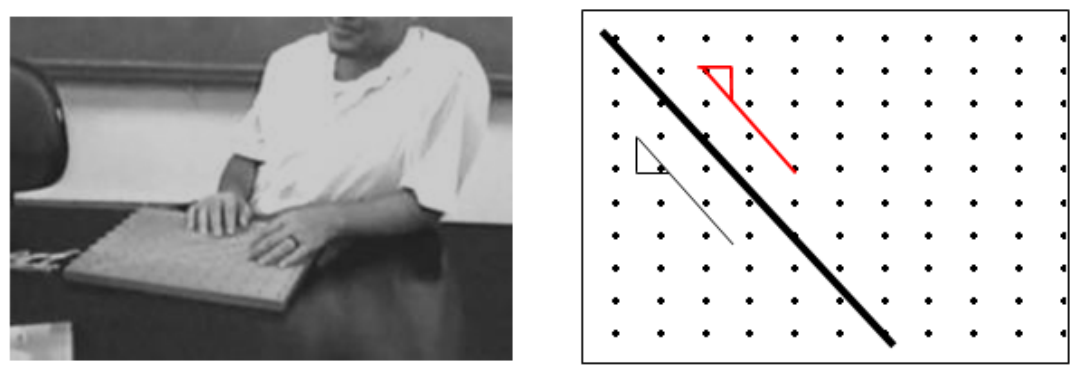

FIGURA 5 - A TAREFA NA FERRAMENTA DE DESENHO E A SOLUÇÃO DE EDSON

O próximo passo era investigar se Edson poderia conectar os conceitos matemáticos à sua prática diária.

Pesquisadora: Na sua vida, no dia a dia, tem figuras simétricas, eixo de simetria e reflexão? Não com esses nomes, é claro, mas aparecem esses conceitos?

Edson: Em objetos sim. Por exemplo: uma flor em cima da minha mesa, outra pessoa pode colocar igual, na mesma mesa, da mesma cor, dai pode ter o eixo de simetria.

O exemplo dado por Edson parece estar associado à ideia de imagem em espelhos, já que ele imagina uma representação em três dimensões (Figura 6). Durante sua fala, Edson vai simulando a situação de dois vasos sobre sua mesa na prancha de desenho, onde cada uma das formas geométricas representa um vaso e o eixo de simetria, um espelho imaginário para ele, é substituído pelo elástico.

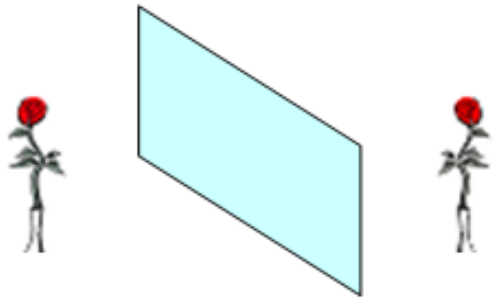

FIGURA 6 - UMA IMAGEM EM 3D

A pesquisadora procura fazê-lo estabelecer outras relações entre os elementos do seu corpo. 


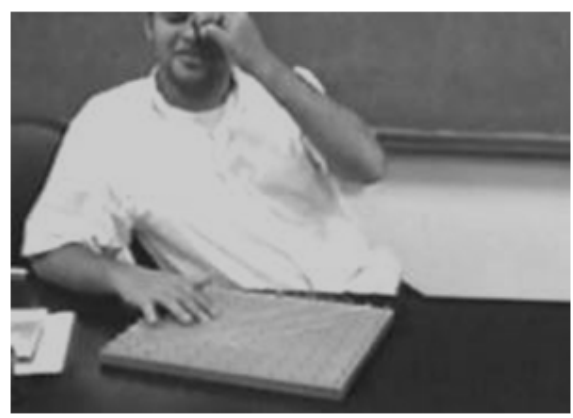

Pesquisadora: E suas duas orelhas são simétricas?

Edson: É (risos) totalmente.

Pesquisadora: E cadê o eixo de simetria?

Edson: Tá no meu nariz (risos).

Pesquisadora: E o que mais você tem de simétrico?

Edson: Meus braços, minhas pernas...

Pesquisadora: Como você dobra suas calças?

Edson: Ah tá! Tem eixo de simetria na calça, na camisa, no blusão. . . em tudo tem.

Pesquisadora: Como você dobra seu cobertor?

Edson: Em dois.

Pesquisadora: Põe ponta com ponta?

Edson: Ponta com ponta. Tem eixo de simetria. Dá inclusive para fazer vários eixos de simetria.

A relação entre os conceitos matemáticos em estudo e a prática cotidiana não foi um processo natural. As intervenções da pesquisadora o auxiliaram a estabelecer tais relações. É interessante realçar que ele se surpreende ao perceber que é possível encontrar simetria (ou eixo de simetria) em muitos objetos que fazem parte de sua prática diária. 


\section{Considerações}

$\mathrm{Na}$ fase inicial do processo empírico, quando o objetivo era determinar o eixo de simetria de figuras feitas em papel, Edson utilizou a estratégia de fazer dobraduras que o permitissem comparar as partes da figura por sobreposição. Essa estratégia o levou a armazenar estados perceptivos táteis (dobrar, sobrepor, comparar) que desencadearam um processo de simulação empregado quando a figura não podia ser dobrada. Desse modo, a experiência de dobrar figuras em partes iguais o fez formular uma representação multimodal que acionou sua imaginação. Edson então declara: Agora eu estou usando a cabeça, como se eu estivesse dobrando com a mão; ou seja, é como se seu sistema sensório-motor estivesse recebendo informações de uma situação perceptiva física, neste caso, um reviver de uma situação que nesse momento só estava "presente" no passado.

Naturalmente a relação entre eixo de simetria e figura, ou melhor, a percepção que o eixo de simetria divide a figura em duas iguais, como declarou Edson, foi essencial para o trabalho com reflexão em torno de um eixo. Os impasses criados nas tarefas iniciais foram superados quando a pesquisadora passou a envolver o sujeito em situações de simulação recorrendo à sua memória visual. A partir da associação que ele passa a estabelecer entre imagens no espelho e imagem de uma figura, a realização das tarefas seguintes torna-se um processo mais rápido.

A conexão entre sua memória visual, produto do passado, e a situação presente permitiu-lhe formular estratégias para a realização das atividades, e o fez gradativamente transformar os conceitos concretos em conceitos abstratos - produtos de sua imaginação. A prática dialógica desenvolve-se com mais naturalidade, mostrando ser essencial, para que se possa estabelecer um diálogo produtivo, conservar a conexão entre os conhecimentos do passado do aprendiz e os conceitos discutidos no presente.

Segundo Meira (2002), "a emergência (e manutenção) de ZDPs depende da freqüência e qualidade de enunciados que explicitamente indiquem relações entre eventos passados e futuros como forma do sujeito justificar a realidade presente". No caso de Edson, havia conceito cotidiano, associado à sua memória visual sobre imagens no espelho, que podia ser articulado como conhecimento do passado; ou seja, havia um conceito cotidiano que podia auxiliar no desenvolvimento do conceito científico - reflexão. Para ele, a apropriação, mesmo que parcial, do conceito de reflexão, foi viabilizada até certo ponto pelo conceito cotidiano - imagens no espelho. Nesse processo, a influência da primeira imagem mental formulada a partir de estímulos hápticos ficou particularmente evidente. 
Para os nossos sujeitos de pesquisa, o desenvolvimento dos conceitos em estudo ocorre a partir do domínio empírico que favorece a formulação de um arsenal de recursos multimodais, e segue em direção ao concreto e à experiência pessoal; ou seja, as conexões que eles estabelecem entre os conceitos matemáticos estudados e sua prática cotidiana (como dobrar o cobertor, o par de sapatos e as calças), só aconteceram quando os conceitos matemáticos assumiram algum significado ou quando foram parcialmente apropriados.

No início da terceira e última sessão, Edson fala sobre os termos matemáticos discutidos nas sessões anteriores, respondendo as intervenções da pesquisadora.

Pesquisadora: O que é eixo de simetria?

Edson: Eixo de simetria é o que divide em duas figuras idênticas.

Pesquisadora: Quando uma figura é simétrica?

Edson: Quando os dois lados são idênticos, ou seja, se eu dobrar a figura fica igual.

Pesquisadora: E como chama essa dobra?

Edson: Eixo de simetria.

Pesquisadora: O que é reflexão?

Edson: É pensar. É desenhar alguma coisa na cabeça. Imaginar. Como você deu o exemplo do espelho. Eu me olhando no espelho. Eu criei uma imagem de mim.

Nas declarações feitas por Edson na última sessão de trabalho continuam presentes o imaginar e a simulação. Naturalmente, com o desenvolvimento das atividades, esses elementos tiveram um papel fundamental para que pudéssemos identificar uma evolução significativa nos conceitos matemáticos em estudo; contudo, alguns pontos devem ser levantados para desencadear discussões.

Para Gallese e Lakoff (2005), o conhecimento conceitual é corporificado, isto é, é mapeado pelo sistema sensório-motor, assim como a imaginação que é estruturada a partir de nossa interação física com o mundo. Para o sujeito deste estudo evidencia-se a importância do corpo nos processos cognitivos. Nossas raízes, provenientes da teoria sociocultural, nos levam a crer que os significados são culturalmente constituídos e motivados pela realidade simbólica expressa, entre outras formas, pela experiência vivida por e com nossos corpos no mundo, e pelas práticas discursivas que relacionam ações e percepções; ainda, pelos processos verbais e não verbais que fazem com que atribuamos sentido, do ponto de vista da sociedade e da cultura, ao mundo do qual fazemos parte. Os resultados de nossas pesquisas com sujeitos cegos apontam também que os sistemas multimodais desempenham papel fundamental no desenvolvimento 
de processos cognitivos, mesmo quando se apoiam em recursos multimodais provenientes de órgãos sensoriais distintos dos usuais.

Nossos resultados têm nos apresentado indícios que nos permitem afirmar que as ferramentas materiais, associadas a outros meios semióticos, favorecem a emergência de signos no sentido vygotskiano. Desse modo, o que no passado foi físico para os aprendizes passa a ser um imaginar, e integra-se ao seu repertório de recursos multimodais, indicando que durante as atividades ocorrem mudanças qualitativas fundamentais no uso dos signos. Assim, o envolvimento do Edson na apropriação das práticas associadas à reflexão e simetria - e de modo geral nossas interações com aprendizes cegos nestes últimos anos - nos permitem apontar que esses aprendizes podem alcançar as mesmas metas que seus pares, desde que se respeite a singularidade do seu perceber o mundo.

\section{REFERÊNCIAS}

BARSALOU, L. W. Grounded Cognition. Annual Review of Psychology, v. 59, p. 617-645, 2008. DOI: 10.1146/annurev.psych.59.103006.093639.

COLE, M.; SCRIBNER, S. Introdução. In: COLE, M.; JOHN STEINER, V.; SCRIBNER, S.; SOUBERMAN, E. (Orgs.). L. S. Vygotsky. A formação social da mente. Tradução de: NETO, J. C.; BARRETO, L. S. M.; AFECHE, S. C. 6. ed. São Paulo: Martins Fontes, 1998. p. 3-19.

CONDE, A. J. M. Definindo a Cegueira e a Deficiência Visual. Disponível em: $<\underline{\text { http:// }}$ www.cesec.org.br/deficiencia/cegueira.htm>. Acesso em: 20/5/2004.

CONDILLAC, E. B.; DEGÉRANDO, J. Textos Escolhidos. Tradução de: MONZANI L. R. et al. São Paulo: Nova Cultura, 1989. Coleção "Os Pensadores".

DAMÁSIO, A. O mistério da consciência: do corpo e das emoções ao conhecimento de si. Tradução de: MOTTA, L. T. 7. ed. São Paulo: Companhia das Letras, 2005.

GALLESE, V.; LAKOFF, G. The brain's concepts: The role of the sensory-motor system in conceptual knowledge. Cognitive Neuropsychology, n. 22, p. 455-479, 2005. DOI: 10.1080/02643290442000310.

GRENIER, D. Construction et étude du fonctionement d'un processus d'enseignement de la symétrie orthogonale en sixième. Tese (Doutorado) - Université Joseph Fourier, Grenoble, 1988. 
HEALY, L. S. Iterative design and comparison of learning systems for reflection in two dimensions. Tese (Doutorado) - University de London, Londres, 2002.

KÜCHEMANN, D. Reflection and rotation. In: HART, K. (Ed.). Children's understanding of mathematics: 11-16. London: John Murray, 1981. p. 137-157.

LEONTIEV. A. N. Activity, Consciousness, and Personality, 1978. Disponível em: $<$ http://www.marxists.org/archive/leontev/index.htm>. Acesso em: 4/11/2007.

MEIRA, L. Zona de desenvolvimento proximal como campo simbólico-temporal: aproximações de um modelo teórico e aplicações para o ensino da matemática. In: I SIMPÓSIO BRASILEIRO DE PSICOLOGIA DA EDUCAÇÃO MATEMÁTICA. Sociedade Brasileira de Psicologia da Educação Matemática. Anais... Curitiba: UFPR/ UTP, PUCPR, 2002. p. 51-57.

OAKLEY, T. Image Schemas. In: GEERAERTS, D.; CUYCKENS, H. (Eds.). Handbook of Cognitive Linguistics. New York: Oxford University Press., 2007. p. 214-235.

van der VEER, R.; VALSINER, J. Vygotsky - Uma sintese. Tradução de: BARTALOTTI, C. C. 4. ed. São Paulo: Loyola, 1996.

VYGOTSKY, L. S. The collected works of L. S. Vygotsky. Problems of general psychology. RIEBER, R.; CARTON, A. (Eds.). Tradução de: SOCHINENII, S. New York: Plenum, 1987. v. 1.

. Obras escogidas $V$ - Fundamentos da defectología. Tradução de: BLANK, J. G. Madrid: Visor, 1997.

.A formação social da mente. In: COLE, M.; JOHN STEINER, V.; SCRIBNER, S.; SOUBERMAN, E. (Orgs.). L. S. Vygotsky. A formação social da mente. Tradução de: NETO, J. C.; BARRETO, L. S. M.; AFECHE, S. C. 6. ed. São Paulo: Martins Fontes, 1998a.

. Pensamento e linguagem. Tradução de: CAMARGO, J. L. 2. ed. São Paulo: Martins Fontes, 1998b. 
